\title{
Efficacy and safety of Curcuma domestica extracts compared with ibuprofen in patients with knee osteoarthritis: a multicenter study
}

This article was published in the following Dove Press journal:

Clinical Interventions in Aging

20 March 2014

Number of times this article has been viewed

\section{Vilai Kuptniratsaikul' \\ Piyapat Dajpratham' \\ Wirat Taechaarpornkul ${ }^{2}$ \\ Montana \\ Buntragulpoontawee ${ }^{3}$ \\ Pranee Lukkanapichonchut ${ }^{4}$ \\ Chirawan Chootip ${ }^{5}$ \\ Jittima Saengsuwan ${ }^{6}$ \\ Kesthamrong Tantayakom ${ }^{7}$ \\ Supphalak Laongpech ${ }^{8}$}

'Department of Rehabilitation

Medicine, Faculty of Medicine Siriraj

Hospital, Mahidol University, Bangkok,

Thailand; ${ }^{2}$ Sirindhorn National Medical

Rehabilitation Center, Ministry of

Public Health, Nonthaburi, Thailand;

${ }^{3}$ Department of Rehabilitation

Medicine, Faculty of Medicine, Chiang

Mai University, Chiang Mai, Thailand;

${ }^{4}$ Department of Rehabilitation

Medicine, Ratchaburi Hospital, Ministry

of Public Health, Ratchaburi, Thailand;

${ }^{5}$ Department of Rehabilitation Medicine,

Songkhla Hospital, Ministry of Public

Health, Songkhla, Thailand; ${ }^{6}$ Department

of Rehabilitation Medicine, Faculty

of Medicine, Khon Kaen University,

Khon Kaen, Thailand; ${ }^{7}$ Department

of Rehabilitation Medicine, Rajvithi Hospital, Ministry of Public Health,

Bangkok, Thailand; ${ }^{8}$ Department of Rehabilitation Medicine, Vachira Phuket Hospital, Ministry of Public Health, Phuket, Thailand

Correspondence: Vilai Kuptniratsaikul Department of Rehabilitation Medicine, Faculty of Medicine Siriraj Hospital,

Mahidol University, 2 Prannok Rd,

Bangkok 10700, Thailand

Tel +662 41975II

Fax +6624114813

Email vilai.kup@mahidol.ac.th
Objective: To determine the efficacy and safety of Curcuma domestica extracts in pain reduction and functional improvement.

Methods: 367 primary knee osteoarthritis patients with a pain score of 5 or higher were randomized to receive ibuprofen $1,200 \mathrm{mg}$ /day or $C$. domestica extracts $1,500 \mathrm{mg} /$ day for 4 weeks. The main outcomes were Western Ontario and McMaster Universities Osteoarthritis Index (WOMAC) total, WOMAC pain, WOMAC stiffness, and WOMAC function scores. Adverse events (AEs) were also recorded.

Results: 185 and 182 patients were randomly assigned into $C$. domestica extracts and ibuprofen groups, respectively. The baseline characteristics were no different between groups. The mean of all WOMAC scores at weeks 0,2 , and 4 showed significant improvement when compared with the baseline in both groups. After using the noninferiority test, the mean difference $(95 \%$ confidence interval) of WOMAC total, WOMAC pain, and WOMAC function scores at week 4 adjusted by values at week 0 of $C$. domestica extracts were noninferior to those for the ibuprofen group ( $P=0.010, P=0.018$, and $P=0.010$, respectively), except for the WOMAC stiffness subscale, which showed a trend toward significance $(P=0.060)$. The number of patients who developed AEs was no different between groups. However, the number of events of abdominal pain/discomfort was significantly higher in the ibuprofen group than that in the $C$. domestica extracts group $(P=0.046)$. Most subjects $(96 \%-97 \%)$ were satisfied with the treatment, and two-thirds rated themselves as improved in a global assessment.

Conclusion: $C$. domestica extracts are as effective as ibuprofen for the treatment of knee osteoarthritis. The side effect profile was similar but with fewer gastrointestinal AE reports in the $C$. domestica extracts group.

Keywords: Curcuma domestica, curcumin, efficacy, ibuprofen, knee osteoarthritis, safety

\section{Introduction}

Knee osteoarthritis $(\mathrm{OA})$ is the most common degenerative joint disorder in the elderly and a major public health problem throughout the world. It is the leading cause of pain and is estimated to be the fourth leading cause of disability among the aging population. ${ }^{1}$ It increases the risks of morbidity because of loss of functional capacity, including difficulty in walking, inability to perform self-care, transferring, and going up and down stairs. Knee OA not only impairs physical functions but also reduces quality of life. ${ }^{2}$ In addition, it is the third leading cause of life-years lost due to disability. ${ }^{3}$

The prevalence of $\mathrm{OA}$ is increasing rapidly. ${ }^{4}$ Its prevalence among Asian countries ranges from $38.1 \%$ to $46.8 \%{ }^{5-7}$ In Thailand, there was a survey among elderly in the community aged more than 50 years using history of knee pain and X-ray finding. 
It was found that the prevalence of knee OA ranged from $34.5 \%$ to $45.6 \%{ }^{8}$ Concerning pharmacologic treatment, nonsteroidal anti-inflammatory drugs (NSAIDs) are the most common prescription for pain relief in OA. ${ }^{9}$ Unfortunately, some patients cannot use NSAIDs due to their adverse effects (AEs) on the gastrointestinal (GI) system, including dyspepsia, ulceration, upper GI bleeding, and perforation of the stomach or duodenum. ${ }^{10-12}$

Curcumin is a spice commonly used for a long time as a coloring agent (yellow) in many kinds of curry powder in Thai food. Evidence from in vitro studies revealed that curcumin has an inhibitory effect on substances involved in the inflammatory pathway, including lipoxygenase, cyclooxygenase (COX), phospholipase, collagenase, elastase, and hyaluronidase. ${ }^{13-16}$ Furthermore, curcumin was found to inhibit the activation of free radical activated transcription factors such as nuclear factor kappa B and nitric oxide synthase. ${ }^{13}$ It also reduces the proinflammatory cytokines: eg, tumor necrosis factor alpha, interleukin (IL)-1 beta, IL-8, and matrix metalloproteinase-13. ${ }^{17,18}$ All of these substances have a major role in the inflammatory joint process. Jackson et $\mathrm{al}^{19}$ reported that curcumin strongly inhibited collagenase and stromelysin expression, suggesting its therapeutic potential for the treatment of arthritis. Concerning safety profiles, curcumin was demonstrated to be safe, even after high-dose ingestion of up to $8,000 \mathrm{mg}$ /day for 3 months. ${ }^{20,21}$

Nowadays, there is scarce information from clinical trials of curcumin in patients with knee OA. In 2009, we performed a single-blind randomized controlled trial to evaluate the efficacy of 2,000 mg/day of Curcuma domestica extracts compared with $800 \mathrm{mg} /$ day of ibuprofen in 107 knee OA patients for 6 weeks. ${ }^{22}$ There were some limitations in that study, including inadequate sample size, subtherapeutic dosage of ibuprofen ( $800 \mathrm{mg}$ per day), a single-blinded assessor, and the unequal frequency of drug intake between the two groups. We decided to conduct this multicenter study with better design: ie, double-blind randomized controlled trial using a lower dosage of curcumin with a shortened duration to 4 weeks, in order to determine the efficacy and safety of $1,500 \mathrm{mg} /$ day of $C$. domestica extracts in pain reduction and functional improvement compared with $1,200 \mathrm{mg} /$ day of ibuprofen.

\section{Materials and methods}

This study was registered at ClinicalTrials.gov (NCT00792818). The study protocol was conducted in accordance with the ethical principles stated in the most recent version of the Declaration of Helsinki. After receiving approval from the Institutional Review Board of eight tertiary hospitals in Thailand, including four hospitals in the central, one in the northern, one in the northeastern, and two in the southern regions of Thailand, we started to recruit knee OA patients from July 2010 to March 2012. The inclusion criteria were primary knee OA patients according to the American Rheumatism Association criteria ${ }^{23}$ who had a numerical rating scale of knee pain of $\geq 5$ out of 10 and age $\geq 50$ years. Patients who had abnormal liver function or renal function, history of peptic ulcer, allergy to curcumin or ibuprofen, or were unable to walk were excluded.

The randomization number was generated by computerized method, and the allocation codes were serially concealed in opaque envelops. After being recruited into the study, every subject received a knee X-ray, which indicated severity according to Kellgren-Lawrence criteria. ${ }^{24}$ Then, all participants were randomly allocated to receive either $1,200 \mathrm{mg} /$ day of ibuprofen or $1,500 \mathrm{mg} /$ day of $C$. domestica extracts. For blinding patients and assessors, both medications were manufactured by the Department of Pharmacy, Siriraj Hospital, Bangkok, Thailand, in the form of a capsule, to make them identical in appearance. The treatment codes were kept by a pharmacist who was not involved in the study process. The patients were asked to take the medication in the form of two capsules after meals three times a day for 4 weeks and not to use other medications during the study. If they had severe pain, they could take tramadol as a rescue medication and were asked to record the amount of drug intake.

The outcomes were evaluated at week 2 and week 4 by the same assessor at each site. The principal outcomes were the Western Ontario and McMaster Universities Osteoarthritis Index (WOMAC), modified Thai version, ${ }^{25}$ and a 6 -minute walk distance. The WOMAC scores were composed of three subscales: ie, WOMAC pain, WOMAC stiffness, and WOMAC function. Each scale ranged from 0 to 10 . The higher score represented more pain, more stiffness, or worse knee functions. For safety concerns, the AEs were recorded if the patients developed new symptoms during the study. Compliance of treatment was assessed using pill count at each visit. At the end of the study, the patients' global assessment and satisfaction were evaluated.

This study was designed as a noninferiority trial under the assumption of significant difference in WOMAC pain score after treatment of \pm 0.5 point. We calculated the sample size by using the nQuery Advisor program, Release 6.0, 2005 (Statistical Solutions, Boston, MA, USA), based on mean change from baseline of our previous study ${ }^{22}$ of a score of 1.9 
with 5\% type I error and $20 \%$ type II error, so the sample size of each group would be 180 . In case of a $10 \%$ dropout rate, the sample size would be 198 per group. Repeated-measures analysis of variance was used to analyze the change over time of the main outcomes. The mean score, mean differences of WOMAC scores, and 6-minute walk distance at week 4 were compared between groups using analysis of covariance and the unpaired $t$-test for noninferiority and equality. The AE and satisfaction levels were analyzed using the chi-square test. The compliance of drug intake was compared using the $t$-test for equality. Per protocol analysis was applied for noninferiority study design. ${ }^{26}$

\section{Preparation of $C$. domestica}

Dried rhizomes of $C$. domestica were ground into powder. The turmeric powder was extracted with ethanol and then evaporated at low pressure to obtain ethanol extract in the form of a semisolid containing oleoresin and curcuminoids. The oleoresin was removed to yield curcuminoids extract (total curcuminoids content between 75\% and 85\%). The peak ratio of curcumin to demethoxycurcumin and bisdemethoxycurcumin in the extract was determined by highperformance thin-layer chromatography. The peak ratio of curcumin to demethoxycurcumin to bisdemethoxycurcumin was 1:0.59:0.23. The extract (calculated for $250 \mathrm{mg}$ of curcuminoids) was filled into a capsule under Good Manufacturing Practices standards.

\section{Results}

A total of 524 knee OA patients were screened, but only 367 could be recruited. One hundred and eighty-two and 185 subjects were randomized to ibuprofen and $C$. domestica extracts groups, respectively. Only 160 patients in the ibuprofen and 171 in the $C$. domestica extracts groups completed the study. The reasons for those subjects being lost to follow-up are presented in Figure 1. There were seven patients in the ibuprofen group and one patient in the $C$. domestica extracts group who were lost to follow-up due to AEs.

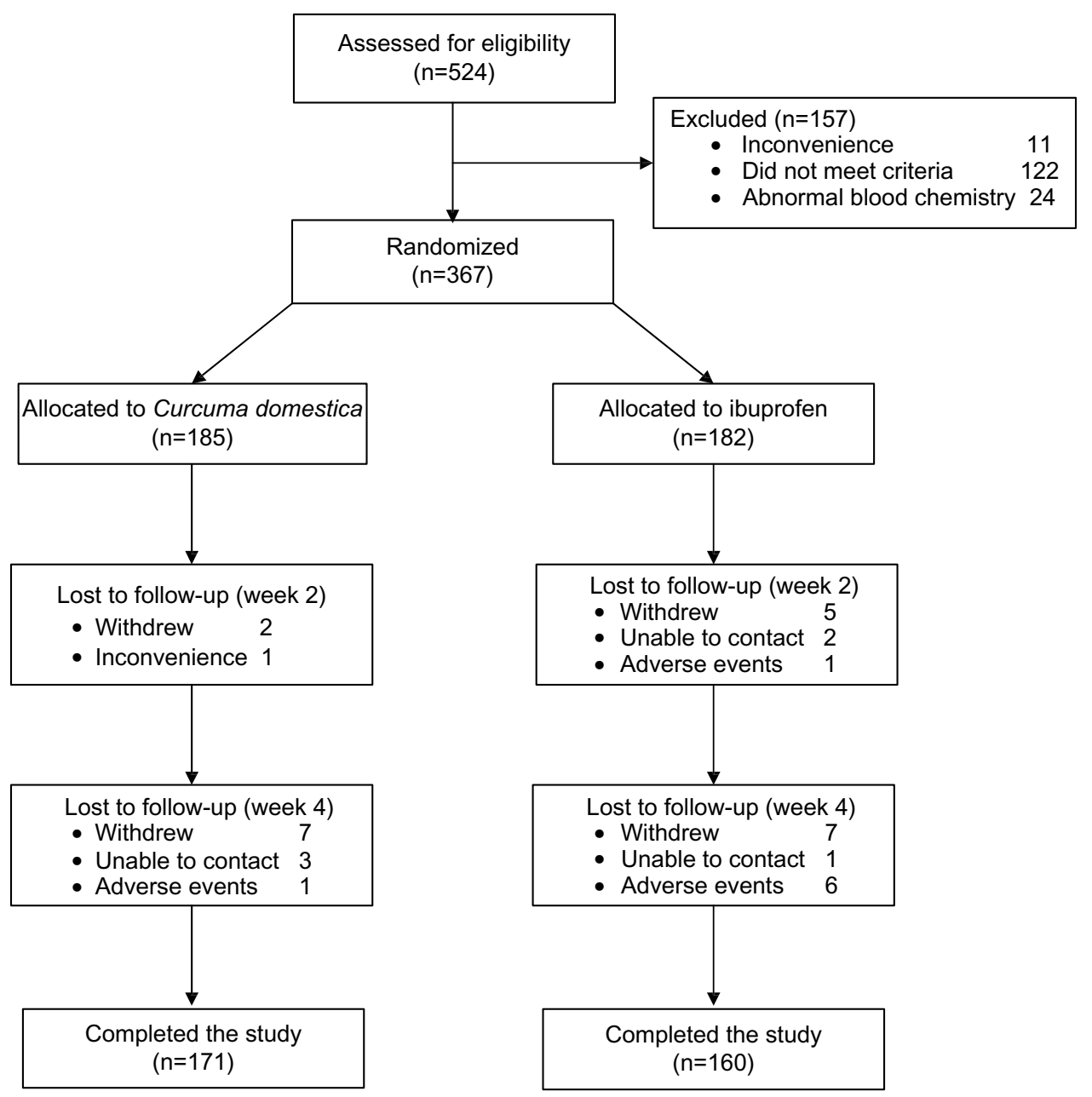

Figure I Flow of participants through stages of a randomized trial. 
The baseline characteristics of participants were no different between the two groups (Table 1). The study population had a mean age of 60 years, a female predominance (approximately $90 \%$ ), and a body mass index of $26 \mathrm{~kg} / \mathrm{m}^{2}$. Nearly $60 \%$ of them had unilateral knee OA. Few patients (7\%) used walking aids. Only one-third used knee support and took pain relief medication. Three-quarters of them performed knee exercise (one to seven times/week). The WOMAC total, WOMAC pain, WOMAC stiffness, and WOMAC function at baseline scores were higher than 5 out of 10 and were no different between groups. The 6-minute walk distance was 304 meters and 310 meters in the ibuprofen and $C$. domestica extracts groups. The numbers of knee X-rays with II-IV grading classified by Kellgren-Lawrence criteria were 138 (86.8\%) versus (vs) 150 $(87.7 \%)$ in the ibuprofen and $C$. domestica extracts groups, respectively, with no difference.

Table I Baseline characteristics of 33I participants

\begin{tabular}{|c|c|c|c|}
\hline Baseline characteristics & $\begin{array}{l}\text { Ibuprofen } \\
(n=160)\end{array}$ & $\begin{array}{l}\text { Curcuma } \\
\text { domestica } \\
\text { extracts } \\
(n=|7|)\end{array}$ & $P$-value ${ }^{a}$ \\
\hline Mean age $\pm S D$ (years) & $60.9 \pm 6.9$ & $60.3 \pm 6.8$ & 0.452 \\
\hline Sex:female & 139 (86.9\%) & I57 (91.8\%) & 0.144 \\
\hline Mean BMI \pm SD $\left(\mathrm{kg} / \mathrm{m}^{2}\right)$ & $26.6 \pm 4.0$ & $26.5 \pm 3.7$ & 0.918 \\
\hline $\begin{array}{l}\text { Mean duration of } \\
\text { pain } \pm S D \text { (months) }\end{array}$ & $52.0 \pm 51.7$ & $5 \mathrm{I} .3 \pm 53.4$ & 0.898 \\
\hline \multicolumn{4}{|l|}{ Knee pain } \\
\hline Unilateral & $92(57.5 \%)$ & $93(54.4 \%)$ & 0.569 \\
\hline Bilateral & $68(42.5 \%)$ & 78 (45.6\%) & \\
\hline Using walking aids & $11(6.9 \%)$ & $12(7.0 \%)$ & 0.959 \\
\hline $\begin{array}{l}\text { Using knee support } \\
\text { (one to seven times/week) }\end{array}$ & $64(40.0 \%)$ & $60(35.1 \%)$ & 0.356 \\
\hline $\begin{array}{l}\text { Routinely taking pain } \\
\text { medicine (three to } \\
\text { seven times/week) }\end{array}$ & $48(30.0 \%)$ & $42(24.6 \%)$ & 0.266 \\
\hline $\begin{array}{l}\text { Exercising knee (one to } \\
\text { seven times/week) }\end{array}$ & 122 (76.3\%) & 127 (74.3\%) & 0.677 \\
\hline WOMAC total \pm SD & $5.2 \pm 1.7$ & $5.3 \pm 1.8$ & 0.611 \\
\hline WOMAC pain \pm SD & $5.4 \pm 1.7$ & $5.3 \pm 1.8$ & 0.899 \\
\hline WOMAC stiffness \pm SD & $5.2 \pm 2.6$ & $5.1 \pm 2.6$ & 0.847 \\
\hline WOMAC functions $\pm S D$ & $5.1 \pm 1.8$ & $5.3 \pm 2.0$ & 0.440 \\
\hline $\begin{array}{l}\text { 6-minute walk distance } \pm S D \\
\text { (meters) }\end{array}$ & $304.5 \pm 83.8$ & $310.9 \pm 84.8$ & 0.489 \\
\hline \multicolumn{4}{|l|}{ X-ray grading } \\
\hline Grade I & 21 (I3.2\%) & 21 (I2.3\%) & 0.543 \\
\hline Grade II & $57(35.8 \%)$ & 74 (43.3\%) & \\
\hline Grade III & $54(34.0 \%)$ & $48(28.1 \%)$ & \\
\hline Grade IV & 27 (I7.0\%) & $28(16.3 \%)$ & \\
\hline
\end{tabular}

Notes: anpaired $t$-test or chi-square test; 'Kellgren-Lawrence grading: $0=$ normal radiograph; I= doubtful pathology; II= minimal osteophytes, possible narrowing, cysts, and sclerosis; $\mathrm{II}=$ moderate, as in definite osteophytes with moderate joint space narrowing; IV= severe, with large osteophytes and definite joint space narrowing. Abbreviations: BMI, body mass index; SD, standard deviation; WOMAC, Western Ontario and McMaster Universities Osteoarthritis Index.
Figure 2 presents the changes over time of the mean (standard deviation) of WOMAC total, WOMAC pain, WOMAC stiffness, and WOMAC function subscales at week 0 , week 2 , and week 4 of both groups using repeated-measures analysis of variance. A within-group comparison of WOMAC scores showed decreased scores in both groups, which meant significant improvement from baseline $(P<0.001)$. However, the between-group comparison showed no differences in WOMAC scores $(P=0.326, P=0.531, P=0.522$, and $P=0.278$ for WOMAC total, WOMAC pain, WOMAC stiffness, and WOMAC function subscales, respectively).

Concerning the effectiveness of $C$. domestica extracts in this study, we compared the primary outcomes at week 4 adjusted by week 0 . The mean, standard deviation, and difference values ( $95 \%$ confidence interval [CI]) of WOMAC total score, WOMAC pain, WOMAC stiffness, and WOMAC function subscales at week 4 are presented in Table 2. All of the WOMAC scores in the C. domestica extracts group seemed to be more than those in the ibuprofen group. However, after using the noninferiority test, the mean difference $(95 \% \mathrm{CI})$ of the WOMAC total, WOMAC pain, and WOMAC function subscales at week 4 adjusted by week 0 of the $C$. domestica extracts group was within 0.5 point, which means that the $C$. domestica extracts group was noninferior to the ibuprofen group $(P=0.010, P=0.018$, and $P=0.010$, respectively), whereas the WOMAC stiffness subscale showed a trend toward significance $(P=0.060)$. In addition, the 6-minute walk distance at week 4 was approximately 350 meters, which was no different between the groups (mean difference and 95\% CI were 7.18 meters and -7.01 to 21.38 meters).

In addition, the number of subjects with $\mathrm{AE}$ occurring during the study was no different between the two groups (35.7\% in ibuprofen vs $29.7 \%$ in the C. domestica extracts group, $P=0.222$, Table 3). Common AEs were dyspepsia, abdominal pain/distension, nausea, loose stool, and pitting edema. For the numbers of events that occurred, the rate of abdominal pain/distension was significantly lower in the C. domestica extracts group than in the ibuprofen group $(10.8 \%$ vs $18.1 \%, P=0.046)$. However, the rates of dyspepsia, nausea, and pitting edema were higher in the ibuprofen group than in the $C$. domestica extracts group (15.9\% vs $11.4 \%$ for dyspepsia, $8.2 \%$ vs $4.9 \%$ for nausea, and $7.1 \%$ vs $3.8 \%$ for pitting edema), but none of these events reached statistical significance. Only the symptom of loose stool was higher in the $C$. domestica extracts group than in the ibuprofen group, also with no difference $(11.9 \%$ vs $8.8 \%, P=0.330)$. There were two patients in the ibuprofen group who had melena. 

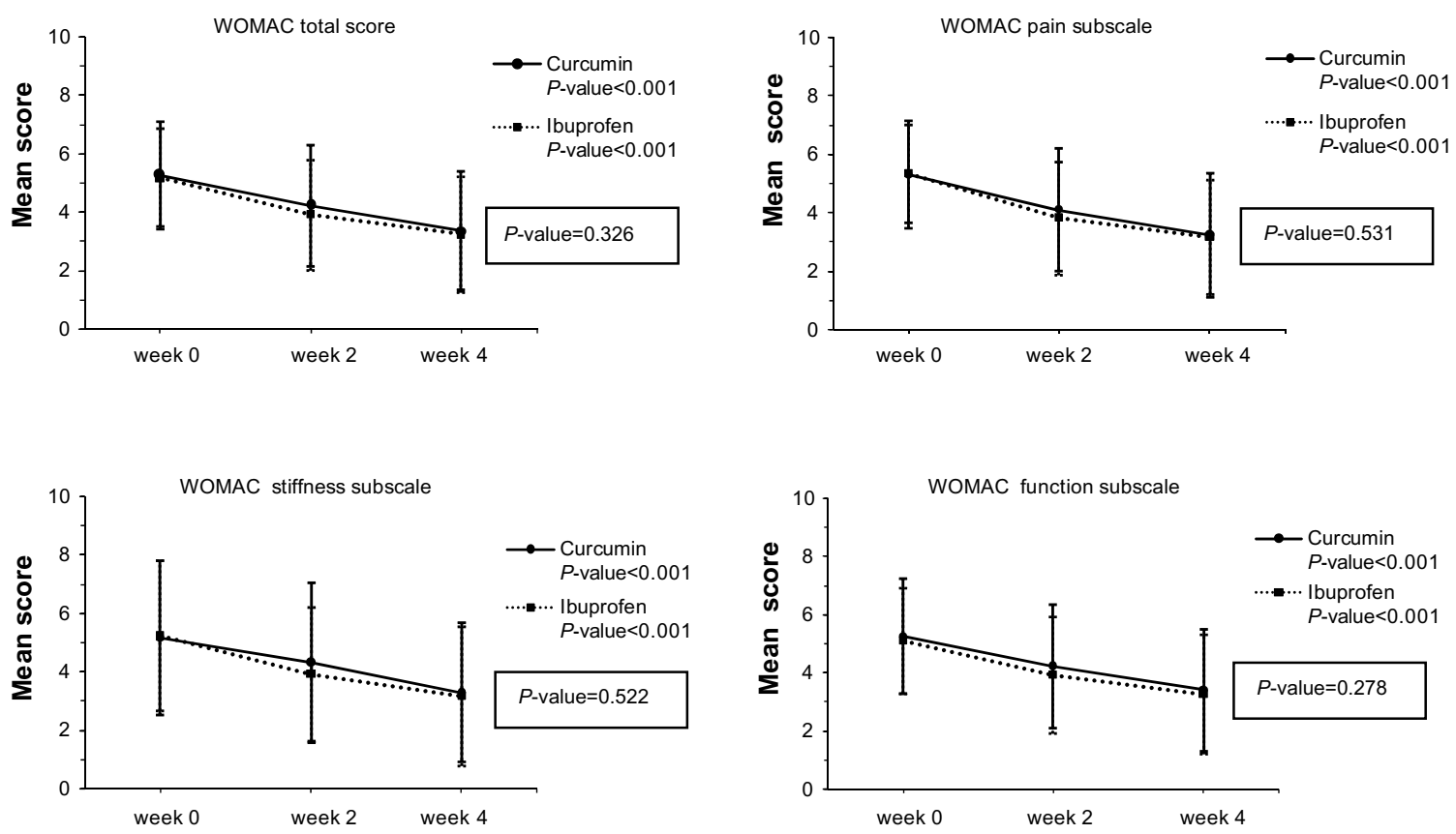

Figure 2 The changes over time of Western Ontario and McMaster Universities Osteoarthritis Index (WOMAC) total, WOMAC pain, WOMAC stiffness, and WOMAC function scores at weeks 0,2 , and 4 of both groups using repeated-measures analysis of variance.

There was no difference in drug compliance between the groups (93.8\% vs $92.6 \%$ in the ibuprofen and C. domestica extracts groups, respectively, $P=0.202)$. Concerning the rescue drug, two (1.1\%) and five $(2.7 \%)$ patients in the ibuprofen group and the $C$. domestica extracts group used tramadol, but no significant difference was found $(P=0.449)$. The patients' global assessment and satisfaction at week 4 also was no different between groups ( $P=0.665$ and $P=0.707$, respectively). Most subjects (96\%-97\%) were satisfied with the treatment, and two-thirds of them rated themselves as improved in a global assessment (Table 4).

\section{Discussion}

In the past decade, evidence in vitro has revealed the efficacy of curcumin in many aspects, including anti- inflammatory, ${ }^{20,27}$ antioxidant, ${ }^{28}$ and anticarcinogenic. ${ }^{29-31}$ We were interested in its anti-inflammatory effect because some patients with knee OA are unable to use NSAIDs due to their gastrointestinal AEs. ${ }^{10-12}$ The mechanism of anti-inflammatory activity of curcumin extracts was demonstrated by the inhibition of many different substances that play a major role in inflammation, including phospholipase, lipoxygenase, COX-2, leukotrienes, thromboxane, prostaglandins, collagenase, elastase, hyaluronidase, tumor necrosis factor- $\alpha$, IL-1, IL-8, and IL-12. ${ }^{13-17}$ In addition, Henrotin et $\mathrm{al}^{32}$ found that diferuloylmethane (the active ingredient of curcumin) protects chondrocytes by inhibiting IL-1 $\beta$, activator protein-1/nuclear factor kappa B, and matrix metalloproteinase- 3 and preventing chondrocyte apoptosis. Lev-Ari et $\mathrm{al}^{33}$ reported an in vitro study of

Table 2 Mean, SD, and difference $(95 \% \mathrm{Cl})$ of WOMAC total, WOMAC pain, WOMAC stiffness, and WOMAC function scores and 6-minute walk distance at week 4 adjusted by week 0 in ibuprofen and Curcuma domestica groups

\begin{tabular}{|c|c|c|c|c|}
\hline $\begin{array}{l}\text { Mean score at week } 4 \\
\text { adjusted by week } 0 \pm S D\end{array}$ & $\begin{array}{l}\text { lbuprofen } \\
(n=160)\end{array}$ & $\begin{array}{l}\text { C. domestica extracts } \\
(n=|7|)\end{array}$ & $\begin{array}{l}\text { Mean difference }{ }^{a} \\
(95 \% \mathrm{Cl})\end{array}$ & $P$-value \\
\hline WOMAC total score & $3.23 \pm 1.97$ & $3.36 \pm 2.04$ & $-0.07(-0.43,0.29)$ & $0.010^{\mathrm{b}}$ \\
\hline WOMAC pain subscale & $3.17 \pm 1.98$ & $3.25 \pm 2.11$ & $-0.09(-0.47,0.29)$ & $0.018^{\mathrm{b}}$ \\
\hline WOMAC stiffness subscale & $3.16 \pm 2.36$ & $3.28 \pm 2.38$ & $-0.15(-0.59,0.29)$ & $0.060^{\mathrm{b}}$ \\
\hline WOMAC function subscale & $3.26 \pm 2.05$ & $3.4 I \pm 2.09$ & $0.06(-0.43,0.32)$ & $0.010^{\mathrm{b}}$ \\
\hline 6-minute walk (meters) & $347.99 \pm 86.60$ & $345.43 \pm 91.66$ & $7.18(-7.01,21.38)$ & $0.320^{c}$ \\
\hline
\end{tabular}

Notes: astimated marginal means week 4 adjusted by week 0 of ibuprofen group minus $C$. domestica extracts group; banalysis of covariance and unpaired $t$-test for noninferiority test; 'analysis of covariance for equality.

Abbreviations: $\mathrm{Cl}$, confidence interval; SD, standard deviation; WOMAC, Western Ontario and McMaster Universities Osteoarthritis Index. 
Table 3 Adverse events (AEs) occurring during study compared between two groups

\begin{tabular}{llll}
\hline Adverse events & $\begin{array}{l}\text { Ibuprofen } \\
(\mathbf{n}=182)\end{array}$ & $\begin{array}{l}\text { Curcuma domestica } \\
\text { extracts } \\
(\mathbf{n}=185)\end{array}$ & P-value $^{\mathbf{a}}$ \\
\hline $\begin{array}{l}\text { Number of patients } \\
\text { with AE }\end{array}$ & $65(35.7 \%)$ & $55(29.7 \%)$ & 0.222 \\
$\begin{array}{l}\text { Number of events } \\
\text { Abdominal pain/ }\end{array}$ & $33(18.1 \%)$ & $20(10.8 \%)$ & $0.046^{\mathrm{b}}$ \\
$\quad$ distension & & & \\
Dyspepsia & $29(15.9 \%)$ & $21(11.4 \%)$ & 0.201 \\
Nausea & $15(8.2 \%)$ & $9(4.9 \%)$ & 0.191 \\
Loose stool & $16(8.8 \%)$ & $22(11.9 \%)$ & 0.330 \\
Melena & $2(1.1 \%)$ & - & 0.245 \\
Pitting edema & $13(7.1 \%)$ & $7(3.8 \%)$ & 0.156 \\
\hline
\end{tabular}

Notes: ${ }^{a}$ Chi-square test, Fisher's exact test; ${ }^{b}$ statistical significance.

curcumin with COX-2 anti-inflammatory agents that showed that it can inhibit COX by reducing prostaglandin E2 level. However, studies of the efficacy of curcumin in knee OA patients are scarce.

There are some clinical studies concerning the efficacy of curcumin. Belcaro et $\mathrm{al}^{34}$ studied the effect of Meriva ${ }^{\circledR}$ (Indena S.p.A., Milan, Italy) 1,000 mg per day (containing curcumin $200 \mathrm{mg}$ /day) combined with NSAIDs or analgesic drugs for 8 months in 100 knee OA patients with Kellgren-Lawrence grade I-II severity. They found that it could significantly improve WOMAC scores and walking distance only in the study group. However, their study used a low dose of curcumin in combination with NSAIDs, not a head-to-head comparison between curcumin and NSAIDs as in our study. The duration of drug intake was 8 months. In addition, subjects in their study were young with a mean age of 44 years and mild severity of knee OA (X-ray grading I-II). These may be the reasons why their outcomes seem to be good. The compliance of drug intake among the groups was not reported.

Another study from India reported a comparative trial concerning the efficacy of RA-11 (Artrex, Mendar; Bioved

Table 4 Patients' global assessment and satisfaction at week 4

\begin{tabular}{|c|c|c|c|}
\hline Variables & $\begin{array}{l}\text { Ibuprofen } \\
(n=160)\end{array}$ & $\begin{array}{l}\text { Curcuma domestica } \\
\text { extracts } \\
(n=|7|)\end{array}$ & $P$-value ${ }^{a}$ \\
\hline Global assessment & & & 0.665 \\
\hline Improved & 102 (63.8\%) & I I 0 (64.3\%) & \\
\hline Indifferent & 52 (32.5\%) & $58(33.9 \%)$ & \\
\hline Deteriorated & $6(3.7 \%)$ & $3(1.8 \%)$ & \\
\hline Satisfaction index & & & 0.707 \\
\hline Satisfied & 153 (95.6\%) & $166(97.1 \%)$ & \\
\hline Indifferent & 7 (4.4\%) & $4(2.3 \%)$ & \\
\hline Unsatisfied & - & I (0.6\%) & \\
\hline
\end{tabular}

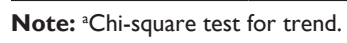

Pharmaceuticals, Inc., Pune, India), the multiplant Ayuravej drug that is composed of Withania somnifera, Boswellia serrata, Zingiber officinale, and Curcuma longa, in 90 patients with knee OA. ${ }^{35}$ Subjects were randomized to have RA-11 or placebo for 32 weeks. Their results were that knee pain score and WOMAC score significantly decreased $(P<0.05$, $P<0.01$ ) only in the study group. However, there were 28 subjects who withdrew before the end of the study. This study was different from ours because it used a mixture of drugs and compared with placebo, whereas we chose curcuminoid extracts and compared with an active controlled drug (ibuprofen).

A study from Thailand carried out by Pinsornsak and Niempoog ${ }^{36}$ in 2012 performed a randomized control trial of the efficacy of $1,000 \mathrm{mg} /$ day of $C$. longa extract as an adjuvant therapy of diclofenac ( $75 \mathrm{mg} /$ day) for 3 months in 88 primary knees with OA. They found no statistical significance between groups in visual analog scale for pain and functions evaluated by Knee Injury and Osteoarthritis Outcome Score. ${ }^{37}$ That means that $C$. longa extract does not add more benefit for subjects than those receiving only diclofenac.

From our previous study in 2009, even though there was a trend toward a greater effect in patients receiving $C$. domestica extracts, we could not definitely conclude that $C$. domestica extracts were as effective as ibuprofen, because the upper limit of the $95 \%$ CI of mean difference in the pain score exceeded the prespecified equivalence limit (one point). This study adjusted some of the methodology to correct those flaws: ie, the frequency and dosage of $C$. domestica extracts and ibuprofen $(1,500 \mathrm{mg} / \mathrm{d}$ vs $1,200 \mathrm{mg} / \mathrm{d}$, respectively, divided into three times per day), the double-blinded controlled trial, and shortening the duration of drug intake from 6 weeks to 4 weeks due to the better trend of outcomes at week 4 from our previous study. ${ }^{22}$ In addition, for precision of outcomes, we chose the narrow range of difference ( \pm 0.5 point) in main outcome after treatment, and we used the $t$-test for noninferiority to determine effect between groups.

One thing that we have concern about is the dosage of ibuprofen used in the active controlled group. Even though ibuprofen at a higher dosage of 1,800 $\mathrm{mg}$ per day can be expected to have higher tissue distribution, decrease proinflammatory synovial fluid cytokine levels, and provide better control of knee symptoms, as reported by Gallelli et al, ${ }^{38,39}$ we still chose a daily dose of $1,200 \mathrm{mg}$ ibuprofen in this study. The reasons were that Thai people have a lower average body weight compared with Caucasians, and our rheumatologist suggested a daily dosage of 800-1,200 mg of ibuprofen in daily practice. Moreover, a higher dosage 
would increase risk of GI AE, especially melena, as presented in this study.

Finally, our results show that the mean differences of all WOMAC scores of the $C$. domestica group (except stiffness subscale) were noninferior to the ibuprofen group, and those values were within a prespecified range of noninferiority limit (0.5 point). The 6-minute walk distance was also no different between groups. Therefore, we can conclude that $C$. domestica extracts were as efficacious as ibuprofen in pain reduction and functional improvement. For safety concerns, C. domestica extracts showed safety profiles better than ibuprofen in terms of abdominal pain/distension. In addition, seven patients in the ibuprofen group were lost to follow-up due to AEs, as compared with one patient in the $C$. domestica extracts group. This evidence supports the safety profile of the $C$. domestica extracts group. Cheng et $\mathrm{al}^{21}$ reported that $C$. domestica extracts can be provided at 2,000 $\mathrm{mg} / \mathrm{d}$ for 6 weeks or an even higher dose of up to $8,000 \mathrm{mg} / \mathrm{d}$ for 3 months without any serious AEs. Moreover, the compliance rate of both drugs in this study was more than $90 \%$. Patients' global assessment of improvement was approximately $64 \%$ in both groups, and more than $95 \%$ of both groups were satisfied with the treatment outcomes. All these documented results confirm the efficacy and safety of $C$. domestica extracts.

\section{Conclusion}

C. domestica extracts are noninferior to ibuprofen for the treatment of knee OA. The AE profile was similar but with fewer GI AE reports in the $C$. domestica extracts group.

\section{Acknowledgments}

The authors would like to thank Mr Suthiphol Udompunturuk and Ms Julaporn Poolium for statistical analyses, and Professor Manee Rattanachaiyanont for reviewing the manuscript. This study was supported by the National Research Council of Thailand (NRCT), the Clinical Research and Collaborative Network (CRCN), and the Thai Government Pharmaceutical Organization (GPO).

\section{Disclosure}

The authors report no conflicts of interest in this work.

\section{References}

1. Fransen M, Bridgett L, March L, Hoy D, Penserga E, Brooks P. The epidemiology of osteoarthritis in Asia. Int J Rheum Dis. 2011;14(2): 113-121.

2. Kim IJ, Kim HA, Seo YI, et al. Prevalence of knee pain and its influence on quality of life and physical function in the Korean elderly population: a community based cross-sectional study. J Korean Med Sci. 2011;26(9):1140-1146.
3. March LM, Bagga H. Epidemiology of osteoarthritis in Australia. Med J Aust. 2004;180(Suppl 5):S6-S10.

4. Suri P, Morgenroth DC, Hunter DJ. Epidemiology of osteoarthritis and associated comorbidities. PM R. 2012;4(Suppl 5):S10-S19.

5. Du H, Chen SL, Bao CD, et al. Prevalence and risk factors of knee osteoarthritis in Huang-Pu District, Shanghai, China. Rheumatol Int. 2005;25(8):585-590.

6. Yoshida S, Aoyagi K, Felson DT, Aliabadi P, Shindo H, Takemoto T. Comparison of the prevalence of radiographic osteoarthritis of the knee and hand between Japan and the United States. J Rheumatol. 2002;29(7): $1454-1458$.

7. Cho HJ, Chang CB, Kim KW, et al. Gender and prevalence of knee osteoarthritis types in elderly Koreans. $J$ Arthroplasty. 2011;26(7): 994-999.

8. Kuptniratsaikul V, Tosayanonda O, Nilkanuwong S, Thamlikitkul V. The epidemiology of knee osteoarthritis patients. J Med Assoc Thai. 2002;85(2):154-161.

9. Seed SM, Dunican KC, Lynch AM. Osteoarthritis: a review of treatment options. Geriatrics. 2009;64(10):20-29.

10. Gumbrevicius G, Milasius A, Sveikata A. Nonsteroidal anti-inflammatory agents: choice between disturbances of gastrointestinal tract and cardiovascular toxicity. Medicina (Kaunas). 2006;42(5):429-439.

11. Gallelli L, Colosimo M, Pirritano D, et al. Retrospective evaluation of adverse drug reactions induced by nonsteroidal anti-inflammatory drugs. Clin Drug Investig. 2007;27(2):115-122.

12. Turajane T, Wongbunnak R, Patcharatrakul T, Ratansumawong K, Poigampetch Y, Songpatanasilp T. Gastrointestinal and cardiovascular risk of non-selective NSAIDs and COX-2 inhibitors in elderly patients with knee osteoarthritis. J Med Assoc Thai. 2009;92(Suppl 6): S19-S26.

13. Bengmark S. Curcumin, an atoxic antioxidant and natural NF kappa B, cyclooxygenase-2, lipooxygenase, and inducible nitric oxide synthase inhibitor: a shield against acute and chronic diseases. J Parenter Enteral Nutr. 2006;30(1):45-51.

14. Oyagbemi AA, Saba AB, Ibraheem AO. Curcumin: from food spice to cancer prevention. Asian Pac J Cancer Prev. 2009;10(6):963-967.

15. Khanna D, Sethi G, Ahn KS, et al. Natural products as a gold mine for arthritis treatment. Curr Opin Pharmacol. 2007;7(3):344-351.

16. Saja K, Babu MS, Karunagaran D, Sudhakaran PR. Anti-inflammatory effect of curcumin involves downregulation of MMP-9 in blood mononuclear cells. Int Immunopharmacol. 2007;7(13):1659-1667.

17. Kim KH, Lee EN, Park JK, et al. Curcumin attenuates TNF- $\alpha$-induced expression of intercellular adhesion molecule-1, vascular cell adhesion molecule-1 and proinflammatory cytokines in human endometriotic stromal cells. Phytother Res. 2012;26(7):1037-1047.

18. Yang Q, Wu S, Mao X, Wang W, Tai H. Inhibition effect of curcumin on TNF- $\alpha$ and MMP-13 expression induced by advanced glycation end products in chondrocytes. Pharmacology. 2013;91(1-2): $77-85$.

19. Jackson JK, Higo T, Hunter WL, Burt HM. The antioxidants curcumin and quercetin inhibit inflammatory processes associated with arthritis. Inflam Res. 2006;55(4):168-175.

20. Chainani-Wu N. Safety and anti-inflammatory activity of curcumin: a component of tumuric (Curcuma longa). J Altern Complement Med. 2003;9(1):161-168.

21. Cheng AL, Hsu CH, Lin JK, et al. Phase I clinical trial of curcumin, a chemopreventive agent, in patients with high-risk or pre-malignant lesions. Anticancer Res. 2001;21(4B):2895-2900.

22. Kuptniratsaikul V, Thanakhumtorn S, Chinswangwatanakul P, Wattanamongkonsil L, Thamlikitkul V. Efficacy and safety of Curcuma domestica extracts in patients with knee osteoarthritis. JAltern Comple Med. 2009;15(8):891-897.

23. Altman R, Asch E, Bloch D, et al. Development of criteria for the classification and reporting of osteoarthritis. Classification of osteoarthritis of the knee. Diagnostic and Therapeutic Criteria Committee of the American Rheumatism Association. Arthritis Rheum. 1986;29(8):1039-1049. 
24. Kellgren JH, Lawrence JS. Radiological assessment of osteo-arthrosis. Ann Rheum Dis. 1957;16(4):494-502.

25. Kuptniratsaikul V, Rattanachaiyanont M. Validation of a modified Thai version of the Western Ontario and McMaster (WOMAC) osteoarthritis index for knee osteoarthritis. Clin Rheumatol. 2007;26(10): 1641-1645.

26. Hauck WW, Anderson S. Some issues in the design and analysis of equivalence trials. Drug Inf J. 1999;33:109-118.

27. Banerjee M, Tripathi LM, Srivastava VM, Puri A, Shukla R. Modulation of inflammatory mediators by ibuprofen and curcumin treatment during chronic inflammation in rat. Immunopharmacol Immunotoxicol. 2003;25(2):213-224.

28. Ringman JM, Frautschy SA, Cole GM, Masterman DL, Cummings JL. A potential role of the curry spice curcumin in Alzheimer's disease. Curr Alzheimer Res. 2005;2(2):131-136.

29. Bar-Sela G, Epelbaum R, Schaffer M. Curcumin as an anti-cancer agent: review of the gap between basic and clinical applications. Curr Med Chem. 2010;17(3):190-197.

30. Johnson JJ, Mukhtar H. Curcumin for chemoprevention of colon cancer. Cancer Lett. 2007;255(2):170-181.

31. Karunagaran D, Rashmi R, Kumar TR. Induction of apoptosis by curcumin and its implications for cancer therapy. Curr Cancer Drug Targets. 2005;5(2):117-129.

32. Henrotin Y, Clutterbuck AL, Allaway D, et al. Biological actions of curcumin on articular chondrocytes. Osteoarthritis Cartilage. 2010;18(2):141-149.
33. Lev-Ari S, Strier L, Kazanov D, et al. Curcumin synergistically potentiates the growth-inhibitory and pro-apoptotic effects of celecoxib in osteoarthritis synovial adherent cells. Rheumatology (Oxford). 2006;45(2):171-177.

34. Belcaro G, Cesarone MR, Dugall M, et al. Efficacy and safety of Meriva ${ }^{\circledR}$, a curcumin-phosphatidylcholine complex, during extended administration in osteoarthritis patients. Altern Med Rev. 2010;15(4):337-344.

35. Chopra A, Lavin P, Patwardhan B, Chitre D. A 32-week randomized, placebo-controlled clinical evaluation of RA-11, an Ayurvedic drug, on osteoarthritis of the knees. J Clin Rheumatol. 2004;10(5):236-245.

36. Pinsornsak P, Niempoog S. The efficacy of Curcuma Longa L. extract as an adjuvant therapy in primary knee osteoarthritis: a randomized control trial. J Med Assoc Thai. 2012;95(Suppl 1):S51-S58.

37. Roos EM, Roos HP, Lohmander LS, Ekdahl C, Beynnon BD. Knee Injury and Osteoarthritis Outcome Score (KOOS)-development of a self-administered outcome measure. J Orthop Sports Phys Ther. 1998;28(2):88-96.

38. Gallelli L, Galasso O, Urzino A, et al. Characteristics and clinical implications of the pharmacokinetic profile of ibuprofen in patients with knee osteoarthritis. Clin Drug Investig. 2012;32(12):827-833.

39. Gallelli L, Galasso O, Falcone D, et al. The effects of nonsteroidal anti-inflammatory drugs on clinical outcomes, synovial fluid cytokine concentration and signal transduction pathways in knee osteoarthritis. A randomized open label trial. Osteoarthritis Cartilage. 2013;21(9): $1400-1408$.
Clinical Interventions in Aging

\section{Publish your work in this journal}

Clinical Interventions in Aging is an international, peer-reviewed journal focusing on evidence-based reports on the value or lack thereof of treatments intended to prevent or delay the onset of maladaptive correlates of aging in human beings. This journal is indexed on PubMed Central, MedLine, the American Chemical Society's 'Chemical Abstracts

\section{Dovepress}

Service' (CAS), Scopus and the Elsevier Bibliographic databases. The manuscript management system is completely online and includes a very quick and fair peer-review system, which is all easy to use. Visit $\mathrm{http}: / /$ www.dovepress.com/testimonials.php to read real quotes from published authors. 